\title{
Strategic Cloud Computing Framework: A Case Study of South African IT Professionals
}

\author{
Andrian Wilby Twala \\ Graduate School of Business Leadership \\ University of South Africa \\ Midrand, South Africa
}

\begin{abstract}
In a challenging business environment, organizations are striving to stay competitive. Cloud computing is changing the way IT services is being provided and managed. Cloud computing is becoming more relevant in that the benefits of cloud computing include reducing infrastructure and maintenance costs, increasing operational efficiencies, availability and flexibility. However, like any other technology, both strategically and operationally, the organizations are not very confident in adoption and using it. Therefore, in an attempt to help South African organizations to leverage off the benefits of cloud computing. This paper focuses on how cloud computing may be strategically adopted and use in South Africa from the context of individual Information Technology Professionals. To achieve these South African organizations require a means to adopt and use cloud computing. To this point, the contribution of this paper is a framework, based on Contingency Theory, Stakeholder Theory and Technology-Organization-Environment Framework (TOE), that South African organization can use to strategically position cloud computing as preferred technology in a uniformed and coordinated manner. This study applies interpretivism philosophy and case study to understand the cloud computing adoption and use in South African organizations. The study participants were purposefully selected based on their knowledge, experience and views on cloud computing. The main contribution of this paper is the strategic cloud computing framework that can be used by decision-makers to strategically adopt and use cloud computing in a uniformed and coordinated manner in South African organizations.
\end{abstract}

Keywords:- Cloud Computing, Stakeholder, Contingency, TOE Framework, South Africa, IT Professionals.

\section{INTRODUCTION}

Information technology (IT) has been used for a long time in support activities in organizations. Due to the current economic conditions in South Africa, organizations are looking into alternative technology such as cloud computing as a way of saving on IT resources, free up existing resources and maintenance costs.

Cloud computing is defined as the internet-based computing in which users can share IT resources in a secure and efficient system [1]. This research paper is about how

\author{
Ray M Kekwaletswe \\ Graduate School of Business Leadership \\ University of South Africa \\ Midrand, South Africa
}

should cloud computing be strategically adopted and use in the context of South African organizations. This paper developed a framework known as strategic cloud computing framework. In this study strategic cloud computing inferences to the organizational strategy in that cloud computing adoption and use is in line with the strategic goals of an organization.

\section{A. Cloud computing attraction}

Cloud computing brings a paradigm shift in how we view capital and operational costs in IT. Cloud computing promises numerous benefits such as reducing infrastructure and maintenance costs, increasing operational efficiencies, improving availability and flexibility of resources [2]. Organizations are considering cloud computing as an alternative technology that will be used as a cost-effective strategy for managing IT costs.

Varia[2] position cloud computing as a solution that offers benefits such as the fast provision of hardware, pay as you use model, shared resources and visualization. Authors Marston, Li, Bandyopadhyay, Zhang and Ghalsasi[3] concurs that cloud computing is appealing because it offers cost-saving, the flexibility of resources and pay as you use of resources.

\section{B. Cloud computing trends}

Cisco[4] report reveals an increase in the use of cloud computing data centres. The report reveals that interest in cloud computing has grown significantly. Gartner estimated spend on cloud computing in the next five years to reach $\$ 1$ trillion[5]. It is stated by Gartner forecasts that the IT spends in South Africa, estimate that by 2019 more than R303 billion will have been spent on cloud computing[6].

\section{Cloud strategic alignment}

As more organizations begin to moving to cloud computing. There is a need to strategically position cloud computing in an organization. In this study, we would propose a framework that can be used by South African organizations to strategically position cloud computing as a preferred technology. The framework is based on stakeholder theory, contingency theory and technologyorganization-environment framework.

This paper consists of eight sections. In section two cloud computing will be defined and discussed. Section three will discuss the theoretical framework. Section four explains the conceptual research framework. Section five would discuss the research methodology. Section six would 
discuss the study findings. Section seven explains the final research framework. The last section gives a study conclusion.

\section{SURVEY OF SCHOLARSHIP}

This section provides an overview of the literature review conducted as part of this study. The next subsection discusses the definitions of cloud computing.

\section{A. Understanding Cloud Computing}

This section introduces cloud computing and the benefits of cloud computing. Cloud computing is considered as a paradigm shift in the way IT resources are being paid for and delivered[7]. The most commonly cited definition is by the National Institute of Standard and Technology
(NIST) which defined cloud computing as "a model for enabling convenient, on-demand network access to a shared pool of configurable computing resources(as an example, networks, servers, storage, applications, and services) that can be rapidly provisioned and released with minimal management effort or service provider interaction" [8].

As shown in Figure 1, cloud computing is composed of five essential characteristics namely broad network access, rapid elasticity, measured service, on-demand self-service and resource pooling. Three service models namely Software as a Service (SaaS), Platform as a Service(PaaS) and Infrastructure as a Service(IaaS) [9]. Cloud computing consists of four deployment models, such as public cloud, private cloud, hybrid cloud and community cloud [3].

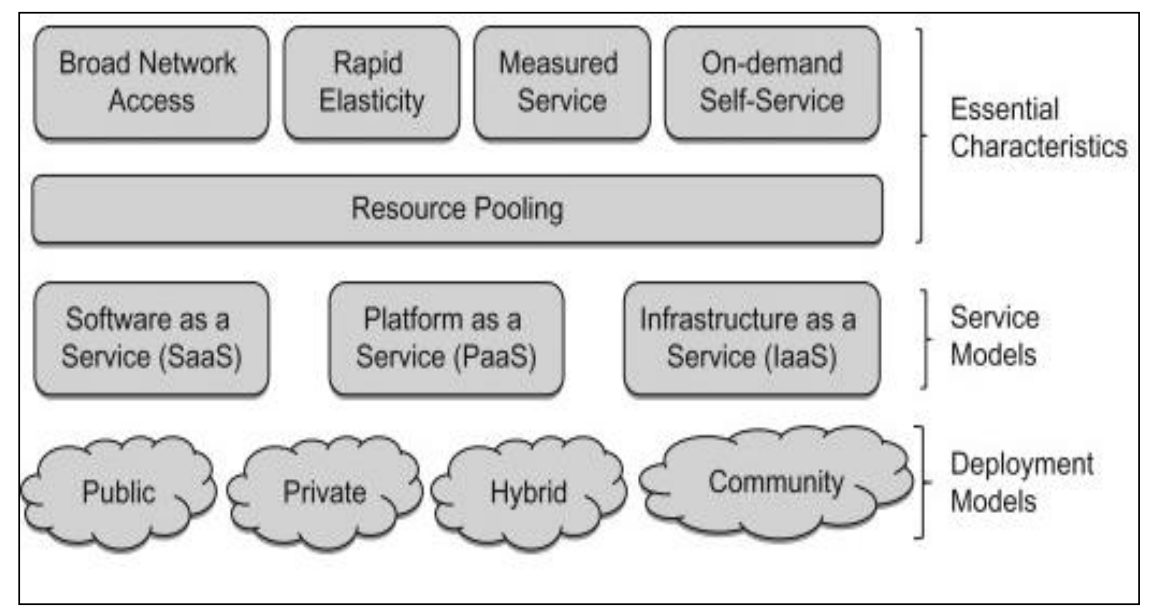

Fig 1:- NIST model of cloud computing[8]

The organization considers various business and technical factors before the adoption and use of cloud computing. Cloud computing offers various benefits such as cost-saving, improved operational efficiencies, immediate access to IT resources, business agility and scalability, accessibility of resources from anywhere at any time[2].

Despite the numerous advantages of cloud computing, there are hindering factors that need to be addressed by organizations, such as security, costs, regulations, contract lock-in, data privacy, compliance challenges and cloud service failure which might prevent management of organization from adopting and using cloud computing.

\section{B. Contingencies for cloud computing}

At the organizational level, the decision to adoption and use cloud computing is centered on the contingencies such as organization strategy, structure and size, and external environment such as various regulations.

In research conducted by Blanton, Watson and Moody[10], the authors used the constructs of contingency theory such as external environment, strategy and structure to understand how an organization would require its structure to create strategies to improve their stance in the market.
Furthermore, the environment in which an organization operates is important in the decision-making process. Jain and Pandey[11] in their study draw attention to the cloud computing environment. The study highlighted the potential risks and potential benefits of adoption and use of cloud computing. The study found that the benefits of cloud computing offset the risks.

In their study Kumar et al[12], they identified business-related issues with regards to cloud computing. These included the policies, cloud computing strategy and technology implementation. Pardeshi[13] highlighted the need to have a strategy for cloud computing. The strategy will provide an alternative solution to the financial crisis of an organization.

Cloud computing is a new business environment. A study by Kaisler, Money and Cohen[14] came up with a decision framework that was meant to assist the decisionmakers when considering to adopt and use the cloud computing and to determine which cloud computing solution meets their organization cloud computing requirements.

Therefore, this study utilized the elements of contingency theory to conceptualize the study's framework. 


\section{Stakeholders for cloud computing}

Stakeholders influence cloud computing adoption and use. Therefore, understanding the roles and goals of stakeholders in the adoption and use of cloud computing is very crucial for the organizations.

As discussed by Yuvaraj[15], cloud computing can bring value to different stakeholders. The study concluded that the main reason for cloud adoption is the benefits such as improved services, availability of services, ease of use and costs reduction.

In the cloud computing context, the relationships between stakeholders are slightly changing. The NIST presented a reference architecture of cloud computing clearly defines a group of actors. The main stakeholders are the cloud provider, who supply the cloud services to interested parties. The cloud consumer is the stakeholder that subscribe or use cloud services. The cloud brokers or enablers who facilitates the delivery of cloud services between provider and customer. The cloud auditors conduct an independent assessment of cloud services.

The study by Haung[16] explored the implementation of IT resources from stakeholder's perspective. The study found that the implementation project can succeed when stakeholder interests are considered and coordinated by top management. The study concluded that stakeholders have an influence when planning for a cloud computing project.

Therefore, this study utilized the elements of stakeholder theory to conceptualize the study's framework.

\section{Factors of cloud computing}

This section discusses the factors that are important in cloud computing adoption and use There have been several studies related to factors of cloud computing. Most of these studies have used the TOE framework to list and discuss factors.

A study by Priyadarshinee[17] used the TOE framework to predict that factors of cloud computing in Indian organizations. The study found factors such as security risks, trust, technology innovation and management style have a significant influence on the adoption of cloud computing.

Another study by Senyo, Effah and Addae[18] was conducted to determine cloud computing factors using the TOE as a research lenses. The study found that, technological factors such as relative advantage and security as the most significant. Organizational factors such as top management and technology readiness. The environmental factors such as competitive pressure and trade partners were found to be significant.

Table 1 below shows previous studies on factors of IT adoption and usage using the TOE framework. The most prominent factors were relative advantage, complexity, compatibility and security in a technological context. Top management support, cost-saving, technology competence were most important in an organizational context. Government regulation and competitor pressure were most important in the environmental context.

\begin{tabular}{|c|c|}
\hline Category & Factors \\
\hline \multirow{4}{*}{ Technology } & Relative advantage [19],[20],[21] \\
\cline { 2 - 2 } & Complexity [19],[20],[22], [23] \\
\cline { 2 - 2 } & Compatibility[19],[20],[22] \\
\cline { 2 - 2 } & Security [19],[22], [24], [25] \\
\hline \multirow{3}{*}{ Organization } & Top management support[19],[20], [21],[26] \\
\cline { 2 - 2 } & Cost-saving [27], [28], [2] \\
\hline \multirow{2}{*}{ Environment } & Techology competence[23], [29] \\
\hline & Government regulation [24],[28] \\
\hline
\end{tabular}

Table 1:- Previous studies using TOE framework

Therefore, this study utilized the elements of TOE framework to conceptualize the study's framework.

\section{THEORETICAL FRAMEWORK}

This study is underpinned by the Contingency Theory, Stakeholder Theory and Technology-OrganizationEnvironment (TOE) framework. The three theories are explained briefly.

\section{A. Contingency Theory}

The basis of contingency theory is that there is no best way of organizing and managing an organization. According to Donaldson[32], contingency theory is defined as a variable that moderates the aspects of organizational characteristics on organizational performance. 
As shown in Figure 2, the contingency theory has components such as organizational structure, organizational strategy and organization performance[33].

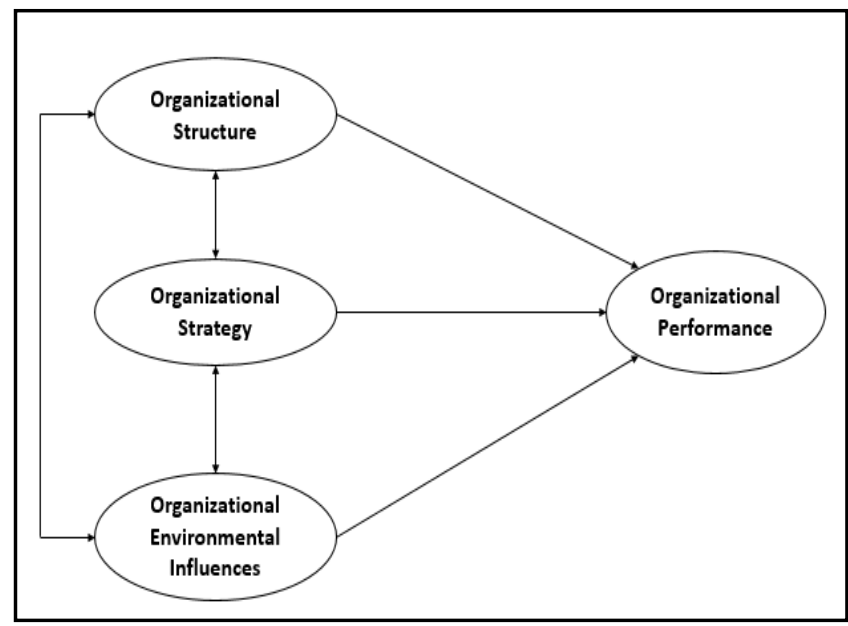

Fig 2:- Contingency Theory[10]

The elements of contingency theory are briefly explained:

$>$ Organizational structure refers to that, there is "no one best way" meaning that no single structure is optimal for all the organization

$>$ Organizational strategy refers to the core of the organization. The long-term direction of an organization.

$>$ Organizational Environmental influences refer to the external pressures or government regulations that the organization need to conform to.

> Organizational performance refers to defined past, present and future accomplishment on the given task against pre-set standards of accuracy and completeness.

The contingency theory is relevant for this paper as it gives the contingency variables for cloud computing adoption and use.

\section{B. Stakeholder Theory}

The stakeholder theory was introduced by Freeman[34] in the year 1984. The stakeholder theory is used to understand the relationship between management and stakeholders. Stakeholders are defined as "any group or individual that can affect or is affected by the achievements of the organization's objectives.

The stakeholder theory describes the value that is being created when stakeholders are working together. The theory originally presented the stakeholder model as a map in which an organization is the hub of a wheel and stakeholders are at the end of spokes around the rim. The stakeholder map is depicted in figure 3 , below.

Stakeholders can influence organizations in several ways, the importance of stakeholders depends on the organization's management perceptions and the stakeholder influence will be more or less proactive or reactive.
The stakeholder theory is relevant for this paper as it identifies the key stakeholders when deciding on the cloud computing adoption and use.

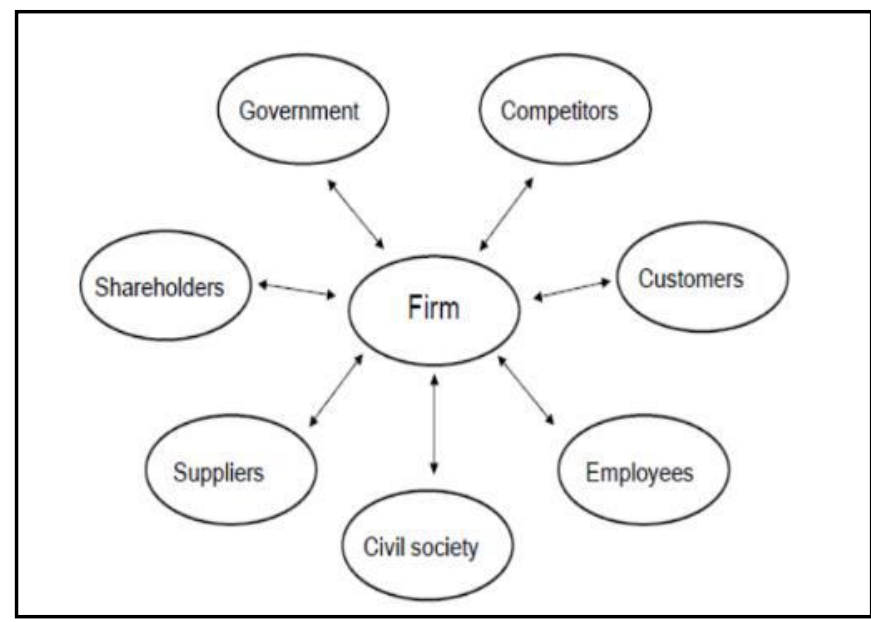

Fig 3:- Stakeholder Theory[34]

\section{Technology-Organization-Environment}

The TOE framework, as depicted in figure 4, below was developed by Tornatzky et al, [35] in 1990. The framework examines the process of how an organization goes about adopting and implementing technological innovations. The adoption and implementation process is believed to be largely influenced by three contexts namely technological factors, organizational factors and environmental factors

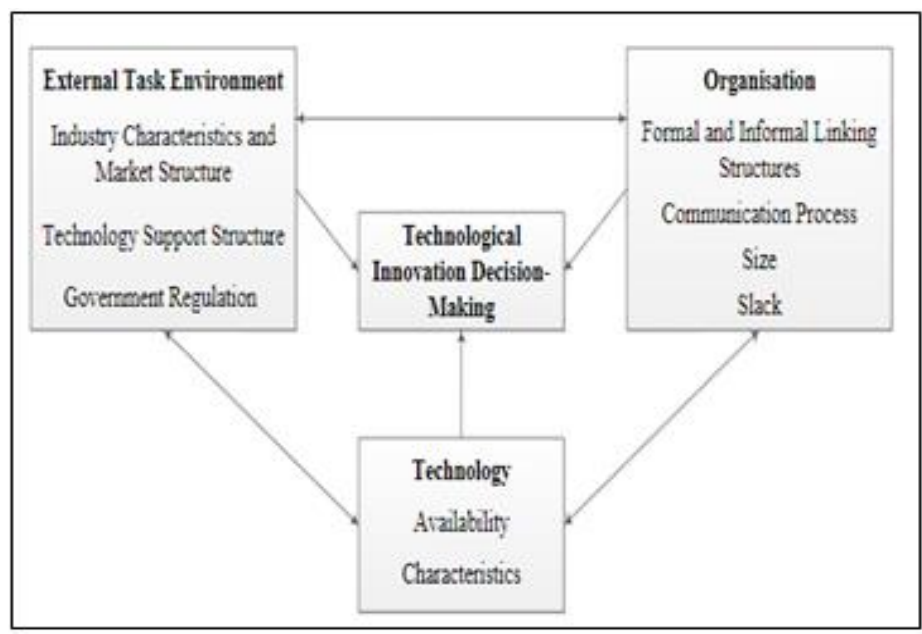

Fig 4:- Technology, Organization, Environment[35]

The components of the TOE are briefly discussed as follows:

$>$ Technology factors refer to the existing and new technology that is owned by the organization

$>$ Organization factors refer to the organizational characteristics such as organization size, organization structure and top management support of the organization

Environment factors refer to external factors that may influence the adoption of technology such as the regulatory environment, competitive pressure and industry pressure in which the organization 
The TOE is relevant for this paper as the decision to adopt and implement cloud computing is influenced by technology, organization and environment factors

\section{CONCEPTUAL RESEARCH FRAMEWORK}

This section sets out the proposed the research conceptual framework. The framework is underpinned by the Contingency Theory, Stakeholder Theory and Technology-Organization-Environment Framework (TOE).
Figure 5 graphically presents the conceptual research framework that guided this study and enables the research questions to be answered. The framework consists of five elements of contingencies elements, technological elements, organizational elements stakeholder elements and environmental elements. The elements will be briefly discussed.

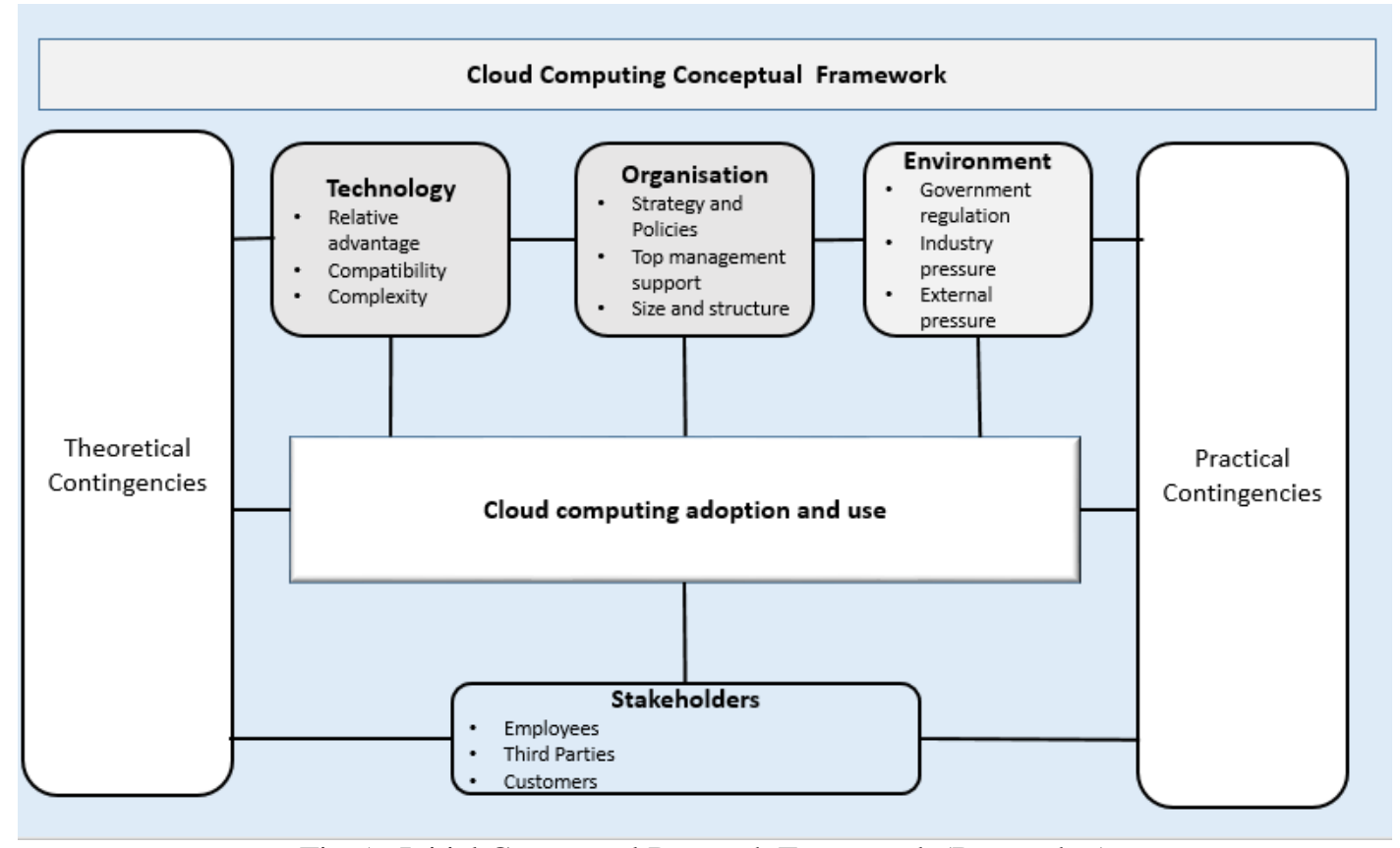

Fig 5:- Initial Conceptual Research Framework (Researcher)

The table 2 below outlines the elements of the conceptual research framework:

\begin{tabular}{|c|c|}
\hline Framework/Theory/Model & Description \\
\hline Stakeholder theory & $\begin{array}{ll} & \\
\text { - Employees } \\
\text { - Third parties } \\
\text { - Customers }\end{array}$ \\
\hline Contingency Theory & $\begin{array}{l}\text { Contingency variables: } \\
\text { - Organisation strategy } \\
\text { - External environment factors } \\
\text { - Characteristics of an organisation such as structure and size }\end{array}$ \\
\hline $\begin{array}{c}\text { Technology-organization-environment } \\
\text { framework }\end{array}$ & $\begin{array}{l}\text { Technology context: } \\
\text { - "Ease of use" of cloud computing } \\
\text { - Characteristics of cloud computing with regards to the complexity } \\
\text { - } \text { Characteristics of cloud computing with regards to compatibility } \\
\text { Organisation context: } \\
\text { - } \text { Role of top management support } \\
\text { - Cloud computing policies and procedures } \\
\text { Environment context: } \\
\text { - An external environment such as government regulations } \\
\text { - Competition within the industry }\end{array}$ \\
\hline
\end{tabular}

Table 2:- Elements of a conceptual research framework 


\section{METHODOLOGY}

Collis and Hussey[36] defined methodology as the "overall approach to the entire process of the research study". The research methodology needs to tie to the study ontology and epistemology in that "given the nature of cloud computing South African reality and to show how the generate new knowledge that is consistent with the epistemology and ontology[37].

\section{A. Research Philosophy}

According to Lincoln and Guba[38], research philosophy refers to the set of beliefs that guide the researcher's assumption. The study followed an interpretivism philosophy to study cloud computing adoption and use. According to Creswell[39], an interpretative philosophy uses the participants' views of the situation being examined.

The study used the interpretivism to solicit IT professional's views, opinions, perceptions and experiences with regards to cloud computing adoption and use. The interpretivism paradigm gave an alternative way of understanding cloud computing adoption and use from the individual's point of view.

\section{B. Research Approach}

There are two types of research approaches; namely, qualitative and quantitative. This study followed a qualitative research approach. According to Creswell[39], qualitative researchers use a language of cases and contexts, to understand the concept of the phenomenon. A qualitative approach is defined as the analysis of data such as information from the proceedings of the interview[40].

This study used the qualitative research approach to gather the empirical data from individual IT professionals with views, experiences and knowledge of cloud computing especially with regards to the South African organization context.

\section{Research Strategy}

Saunders et al [41]defined research strategy as "the general plan of how the researcher will go about answering the research questions". Another definition by Bryman and Bell[42] defined a research strategy as "a general orientation to the conduct of research".

The study adopted a case study as a research strategy. Creswell[39] defines a case study as the study of an issue explored through one or more cases within a bounded system. Yin[43], defines case study research as a practical review that probes a current event within a day-to-day environment when the limitations between the event and environment are not well defined. A case study based on a purposive sampling technique was utilized to gather empirical data through individual participants views, opinions and experience about cloud computing. The participants were chosen to give an alternative way of understanding cloud computing adoption and use from the individual's point of view.

\section{Research Design}

This section describes how the study was conducted. According to Mouton[44], a research design is a plan or blueprint of how you intend conducting the research. The section outlines the unit of analysis, study population, sampling technique and size.

\section{Unit of Analysis}

The unit of analysis describes the level at which the research is performed. Babbie[45] defines the "unit of analysis" as the "what" or "who," being studied. The paper analysis individual IT professionals in South Africa. That is, the unit of analysis is the individuals.

\section{Study Population}

A study population is an aggregation of individuals, events and other interesting elements[46]. It is from a population where a sample is selected. The study population influences the sampling process[47].

The population was limited to the individuals who are working in the IT sector in South Africa.

\section{$>$ Sampling Method}

According to Bryman and Bell[42] sampling technique is how sample size is selected from the study population. A sampling method can be classified as probability and nonprobability.

This study used the purposive sampling technique to select the participants who are knowledgeable with cloud computing to provide the information required by the interview guide. According to Creswell[39], purposive sampling focuses on a particular characteristic of a population that of interest. The participants of the study were chosen base on their experiences and perceptions on cloud computing adoption and use from their own perspectives.

\section{> Study Participants}

The participants of this study included individuals IT professionals who have knowledge, experiences and views about cloud computing. The exact number of participants cannot be determined in qualitative research before the study is carried out. The researcher has specially selected participants who can contribute to the research subject and who are willing to share their experiences.

\section{E. Data Collection methods}

Kothari[48] described data collection as a systematic gathering of information that addresses the research problem using various techniques. The primary data was collected through interviews. Data collection associated with qualitative research will be unstructured using open-ended, semi-structured and unstructured interviews.

Therefore, an interview guide was developed in order to address the research objectives. The study collected primary data through semi-structured interviews with individuals from IT professionals such as managers, professionals, experts and consultants. 
The semi-structured interviews were carried out at the place agreed with participants. According to Baker and Edwards[49], a sample of 12 and 60 are the guideline for a qualitative study. This was well within a minimum saturation point to draw inferences.

\section{F. Data Analysis}

Yin [43] recommends that for optimal benefit from data analysis, the researcher methodically arranges and sets up the data to be analyzed. The face to face interviews was electronically recorded and then transcribed for data analysis purposes.

The data analysis was qualitative in nature. An appropriate qualitative analysis method such thematic analysis was used to analyze and interpret data [50]. The themes were developed based on the study research objectives. Tracy [51]states that once the data is gathered the researcher will categorize the data according to the themes identified. Creswell[39] suggest that data analysis in qualitative research consists of preparing and organizing the data for analysis, reducing the data into themes through a process of coding and condensing codes.

The theoretical thematic analysis helps the researcher to interpret the research data based on research questions through which the theoretical lens affects these research questions.

Table 3 below summarizes the research philosophy, research approach, research strategy, research design, data collection methods and data analysis.

\begin{tabular}{|c|c|}
\hline Details & Description \\
\hline Research Paradigm & Interpretivism paradigm \\
\hline Research Approach & Qualitative research approach \\
\hline Research Strategy & Case Study \\
\hline Unit of analysis & The unit of analysis is the individuals \\
\hline Study population & Individual IT professionals \\
\hline Sampling technique & The purposive sampling \\
\hline Data collection methods & $\begin{array}{c}\text { Semi-structured interviews were used to collect primary data to give an in- } \\
\text { depth analysis }\end{array}$ \\
\hline Data analysis & A thematic analysis was used to analyse the data. \\
\hline
\end{tabular}

Table 3:- Research Methodology

\section{DISCUSSION OF FINDINGS}

The goal of this study was to determine how cloud computing could be strategically adopted and used in the South African organization's context. Semi-structured interviews were conducted using a purposive sampling technique. Four themes were identified to answer the research questions namely understanding cloud computing, contingencies of cloud computing, stakeholders and factors of cloud computing.

\section{A. Theme1: Understanding cloud computing}

The purpose of theme one was to understand cloud computing through the eyes of IT professionals. Cloud computing refers to a model that allows cloud users to log into computer resources such as servers, network and data storage capacities via the internet [1].

The findings indicated that the participant has a good knowledge of cloud computing. The understanding of cloud computing is consistent with the literature[1],[8],[52]. Moving to the cloud should be a planned decision. The requirements include the regulation requirements, choosing the right type of cloud service model, staff competencies, and top management support. Participants managed to list all the requirements to be taken into account before moving to the cloud computing environment. The findings concur with the study by Scholtz, Govender \& Gomez[24], where the study found factors such as regulation requirements, availability and data privacy as important factors when moving to the cloud computing.

Cloud computing is seen as an idea that would bring down the costs of hardware, by providing immediate access to hardware resources, without capital investments [53]. The public cloud is the most popular choice of cloud deployment and the software as a service is the main concept behind cloud computing regardless of deployment model.

The findings concur with the findings of a study by Erdogmus[54], where the study found that Software as a service is considered to be the main concept behind cloud computing regardless of deployment model.

\section{B. Theme 2: Contingencies for cloud computing}

The purpose of theme two was to analyze the practical and theoretical contingencies for cloud computing. The paper analyzed contingencies such as organizational strategy, organizational structure and external environment.

The organizational strategy was seen as important elements when adopting and using cloud computing. The strategy aligned the technology towards organizational goals. The findings were in line with a study by Mital, 
Pearce and Robinson [55] where the authors defined the organizational strategy as a plan for interacting with the environment to achieve the organizational goals.

In the environmental context, the factors such as competition pressure, government policy, power outages and network bandwidth costs seem to influence the adoption and use of cloud computing. The business environment in South Africa is not the same as developed countries with regards to politics and culture. The infrastructure is unique to the South African environment, competition pressure plays a significant role in the adoption and use of cloud computing. Other factors that influence the adoption of cloud computing are the stable power availability and the costs of connectivity such as broadband and bandwidth costs seem to be restricting the update of cloud computing by organizations in South Africa.

According to Borgman et al[56], the size of an organization can be a challenge the could facilitate the adoption and use of cloud computing. This construct gave a mixed-view as to whether the structure and size of an organization might influence the adoption and use of cloud computing. The empirical evidence shows that small and medium-sized organization tend to be more creative and innovative when adopting and using cloud computing.

\section{Theme 3: Stakeholders for cloud computing}

The purpose of theme three was to identify the stakeholders for cloud computing. The findings from the interviews showed that there was a general consensus on stakeholder involvement.

The participant highlighted the importance of stakeholder management when deciding on adoption and use of cloud computing within an organization. Thus, the relevant stakeholder should be identified and involved earlier in the adoption and use of cloud computing.

The findings of the study concur with the literature. A study by Hambrick and Cannella[57] stressed the importance of involving people early on in development and debate of strategic options.

The findings further show that the role of stakeholders in organization decision-making is gaining more and more attention.

\section{Theme 4:Factors of cloud computing}

The main objective of theme four was to examine the factors of cloud computing adoption and use. Most of the studies used the TOE framework to identify cloud computing factors. The TOE framework was put forward by DePietro[58].

The following factors enable the cloud computing adoption and use were identified such as relative advantage, top management support, organization size, compatibility and complexity.

The relative advantage of cloud computing technology emerged to be the reason why organizations are adopting and using cloud computing technology such to reduce the cost of IT, ease of use, reliability, improved IT services. The findings concur with the literature that relative advantage influences usage and adoption of cloud computing [18],[22]

The top management support will influence the adoption and use of cloud computing in an organization. The findings concur with the study of Talmizie, Ibrahim, \& Chuprat[26]on assessing the support of top management in the adoption and use of cloud computing

The large organizations it is very difficult to adopt to the new system such as cloud computing and abandon their current systems. The cloud computing benefits such as costsaving, operational efficiencies, immediate access to IT resources, accessible from anywhere at any time[2], are the reasons for organizations switch from their in-house system to a cloud-based system.

Complexity is the degree to which an innovation is perceived as relatively difficult to understand and use. Complexity influences the adoption and use of cloud computing[22],[20].

Compatibility refers to the degree to which cloud computing is perceived as consistent with the current situation in organizations is exhibited. Technical compatibility influences the adoption and use of cloud computing [22],[20].

\section{STRATEGIC CLOUD COMPUTING FRAMEWORK}

This section outlines the proposed strategic cloud computing framework. The framework was developed by triangulating from the literature review and the research findings. The new elements from empirical findings were incorporated into the framework.

Figure 6 below, depicts the strategic cloud computing framework. The elements from strategic cloud computing are described in table 4: 


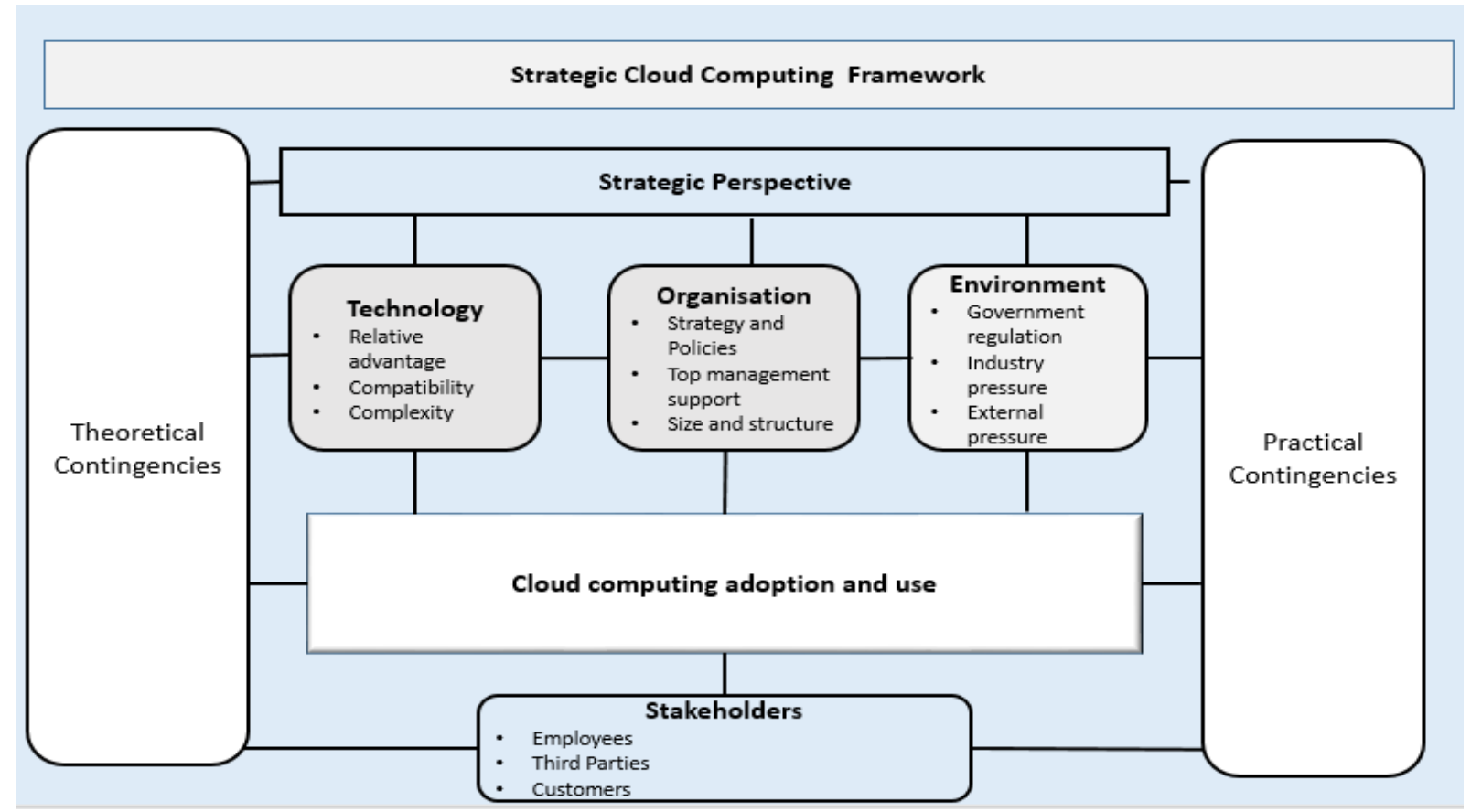

Fig 6:- Strategic cloud computing framework (Researcher)

Table 4 below contextualise the elements of the strategic cloud computing framework:

\begin{tabular}{|c|c|}
\hline Framework/Theory/Model & Description \\
\hline Strategic perspective & $\begin{array}{l}\text { - The strategic intent of moving to cloud computing was defined } \\
\text { - Identify which workloads to move to the cloud } \\
\text { - Determine stakeholders, management and employees who will be involved in } \\
\text { assessing cloud. } \\
\text { - Determine the deployment models and the services from the cloud. }\end{array}$ \\
\hline Stakeholder theory & $\begin{array}{ll} & \text { Stakeholder: } \\
\text { - } & \text { Employees } \\
\text { - Third parties } & \\
\text { - Customers } & \end{array}$ \\
\hline Contingency Theory & $\begin{array}{l}\text { Contingency variables: } \\
\text { - Organisation strategy } \\
\text { - External environment factors } \\
\text { - Characteristics of an organisation such as structure and size }\end{array}$ \\
\hline $\begin{array}{c}\text { Technology-organization-environment } \\
\text { framework }\end{array}$ & $\begin{array}{l}\text { Technology context: } \\
\text { - "Ease of use" of cloud computing } \\
\text { - Characteristics of cloud computing with regards to the complexity } \\
\text { - Characteristics of cloud computing with regards to compatibility } \\
\text { Organisation context: } \\
\text { - Role of top management support } \\
\text { - Cloud computing policies and procedures } \\
\text { Environment context: } \\
\text { - An external environment such as government regulations and Competition } \\
\text { within the industry }\end{array}$ \\
\hline
\end{tabular}




\section{CONCLUSION}

The aim of this paper was to develop a strategic cloud computing framework, that organizations can undertake in order to strategically position cloud computing. This was done by identifying how cloud computing manifest in the South African context, the cloud computing contingencies and the factors that might influence its adoption and use. A systematic literature review was used to gather relevant information and the empirical data was critically analyzed in order to identify knowledge gaps and fill them.

Findings show that available related to the adoption and use of cloud computing is mostly at the organizational level, but none are in the context of individual information technology professionals. This paper brings the individual's point of view on how cloud computing can be adopted and use in an organization. There is a need for a strategic cloud computing framework in the context of individual IT professionals that would help to strategically position cloud computing in the organization in a coordinated manner. The framework identified five components that are necessary to achieve the research objectives.

This research adds value by giving individuals a voice, in which individual experiences, views and opinions on how cloud computing can be adopted and used in an organization. The interpretivism philosophy stance was used to give an alternative way of understanding cloud computing adoption and use from the individual's point of view.

Finally, with the strategic cloud computing framework produced from this study. The framework will contribute to practitioners with the decision making or be used as a guideline in how to address the adoption and use of cloud computing sensitively to the context in which it takes place.

\section{REFERENCES}

[1]. B. Hayes, "Cloud computing," Commun. ACM, vol. 51, no. 7, p. 9, Jul. 2008, doi: $10.1145 / 1364782.1364786$.

[2]. J. Varia, "Migrating your existing applications to the AWS cloud," A Phase Driven Approach to Cloud Migr., 2010.

[3]. S. Marston, Z. Li, S. Bandyopadhyay, J. Zhang, and A. Ghalsasi, "Cloud computing - The business perspective," Decis. Support Syst., vol. 51, no. 1, pp. 176-189, Apr. 2011, doi: 10.1016/j.dss.2010.12.006.

[4]. Cisco, "Cisco Global Cloud Index: Forecast and Methodology , 2014-2019," White Paper, 2014. http://www.cisco.com/en/US/solutions/collateral/ns34 1/ns525/ns537/ns705/ns1175/Cloud_Index_White_Pa per.html\#wp9000816 (accessed Aug. 28, 2017).

[5]. C. STAMFORD, "Gartner Says Global IT Spending to Grow $0.6 \%$ in 2019," 2019. https://www.gartner.com/en/newsroom/pressreleases/2019-04-17-gartner-says-global-it-spendingto-grow-1-1-percent-i\#targetText=The shift of enterprise IT,from \%24399 billion in 2018. (accessed Apr. 29, 2020).
[6]. C. STAMFORD, "Gartner Forecasts IT Spending in South Africa Will Grow 3.9\% in 2019," 2019. https://www.gartner.com/en/newsroom/pressreleases/2019-07-24-gartner-forecasts-it-spending-insouth-africa-will-gr (accessed Apr. 29, 2020).

[7]. S. Marston, Z. Li, S. Bandyopadhyay, J. Zhang, and A. Ghalsasi, "Cloud computing - The business perspective,” Decis. Support Syst., vol. 51, no. 1, pp. 176-189, 2011, doi: 10.1016/j.dss.2010.12.006.

[8]. P. Mell and T. Grance, "The NIST Definition of Cloud Computing Recommendations of the National Institute of Standards and Technology," Natl. Inst. Stand. Technol. Inf. Technol. Lab., vol. 145, p. 7, 2011, doi: 10.1136/emj.2010.096966.

[9]. S. Mathew, "Implementation of Cloud Computing in Education - A Revolution," Int. J. Comput. Theory Eng., vol. 4, no. 3, pp. 473-475, 2012, doi: 10.7763/IJCTE.2012.V4.511.

[10]. J. E. Blanton, H. J. Watson, and J. Moody, "Toward a Better Understanding of Information Technology Organization: A Comparative Case Study," MIS Q., vol. 16, no. 4, p. 531, 1992, doi: 10.2307/249735.

[11]. A. Jain and U. S. Pandey, "Role of cloud computing in higher education," Int. J. Adv. Res. Comput. Sci. Softw. Eng., vol. 3, no. 7, p. pp 966-972, 2013.

[12]. B. Li and S. Kumar, "Should You Kill or Embrace Your Competitor: Cloud Service and Competition Strategy," Prod. Oper. Manag., 2018, doi: 10.1111/poms.12843.

[13]. V. H. Pardeshi, "Cloud Computing for Higher Education Institutes: Architecture, Strategy and Recommendations for Effective Adaptation," Procedia Econ. Financ., vol. 11, no. 14, pp. 589-599, 2014, doi: 10.1016/S2212-5671(14)00224-X.

[14]. S. Kaisler, W. H. Money, and S. J. Cohen, "A Decision Framework for Cloud Computing," 2012 45th Hawaii Int. Conf. Syst. Sci., pp. 1553-1562, 2012, doi: 10.1109/HICSS.2012.52.

[15]. M. Yuvaraj, "Perception of cloud computing in developing countries," Libr. Rev., 2016, doi: 10.1108/LR-02-2015-0015.

[16]. L. K. Huang, "Exploring factors affecting top management support of IT implementation: a stakeholders' perspective in hospital," J. Inf. Technol. Manag., vol. XXVI, no. 1, pp. 31-45, 2015, [Online]. Available: http://jitm.ubalt.edu/XXVI-1/article3.pdf.

[17]. P. Priyadarshinee, R. D. Raut, M. Kumar, and B. B. Gardas, "Computers in Human Behavior Understanding and predicting the determinants of cloud computing adoption : A two-staged hybrid SEM - Neural networks approach," vol. 76, 2017, doi: 10.1016/j.chb.2017.07.027.

[18]. P. K. Senyo et al., "Factors influencing cloud computing adoption for e-government implementation in developing countries," J. Syst. Inf. Technol., 2016, doi: 10.1108/JEIM-09-2014-0094.

[19]. P. K. Senyo, J. Effah, and E. Addae, "Preliminary insight into cloud computing adoption in a developing country," J. Enterp. Inf. Manag., 2016, doi: 10.1108/JEIM-09-2014-0094. 
[20]. T. Oliveira, M. Thomas, and M. Espadanal, "Assessing the determinants of cloud computing adoption: An analysis of the manufacturing and services sectors," Inf. Manag., vol. 51, no. 5, pp. 497510, Jul. 2014, doi: 10.1016/j.im.2014.03.006.

[21]. C. Low, Y. Chen, and M. Wu, Understanding the determinants of cloud computing adoption, vol. 27, no. 4. 2013.

[22]. H. Gangwar, H. Date, and R. Ramaswamy, "Understanding determinants of cloud computing adoption using an integrated TAM - TOE model Introduction," J. Enterp. Inf. Manag., vol. 28, no. 3, pp. 250-275, 2013, doi: 10.1108/JEIM-08-2013-0065.

[23]. W. Klug, "Factors Affecting Cloud Computing Adoption Among Universities," Issues Inf. Syst., vol. 16, no. 3, pp. 1-10, 2015.

[24]. B. Scholtz, J. Govender, and J. M. Gomez, "Technical and Environmental Factors Affecting Cloud Computing Adoption in the South African Public Sector," CONF-IRM 2016 Proc., 2016, Accessed: Mar. 24, 2020. [Online]. Available: http://aisel.aisnet.org/confirm2016.

[25]. K. Van Der Schyff and K. Krauss, "Higher Education Cloud Computing in South Africa: Towards Understanding Trust and Adoption issues," South African Comput. J., vol. 53, Dec. 2014, doi: 10.18489/sacj.v55i0.254.

[26]. M. Talmizie, R. Ibrahim, and S. Chuprat, "ScienceDirect ScienceDirect A Review on Cloud Computing Acceptance Factors," vol. 00, 2018, doi: 10.1016/j.procs.2017.12.200.

[27]. M. Odeh, G. -Perez, and A. \& Warwick, "Cloud Computing Adoption at Higher Education Institutions in Developing Countries: A Qualitative Investigation of Main Enablers and Barriers," Int. J. Inf. Educ. Technol., vol. 7, no. 12, pp. 921-927, 2017, doi: 10.18178/ijiet.2017.7.12.996.

[28]. M. Willett and R. Von Solms, "Cloud-based Email Adoption at Higher Education Institutions in South Africa.," J. Int. Technol. Inf. Manag., vol. 23, no. 2, pp. 17-29, 2014, [Online]. Available: https://core.ac.uk/download/pdf/55335428.pdf.

[29]. O. C. Akin, T. M. Fagbola, and C. Y. Daramola, "The Impact and Challenges of Cloud Computing Adoption on Public Universities in Southwestern Nigeria," Int. J. Adv. Comput. Sci. Appl., vol. 5, no. 8, pp. 13-19, 2014, doi: 10.14569/IJACSA.2014.050803.

[30]. H. M. Sabi, F. E. Uzoka, K. Langmia, and F. N. Njeh, "International Journal of Information Management Conceptualizing a model for adoption of cloud computing in education," Int. J. Inf. Manage., vol. 36, no. 2, pp. 183-191, 2016, doi: 10.1016/j.ijinfomgt.2015.11.010.

[31]. F. Alharbi, A. Atkins, and C. Stanier, "Understanding the determinants of Cloud Computing adoption in Saudi healthcare organisations," Complex Intell. Syst., vol. 2, no. 3, pp. 155-171, 2016, doi: 10.1007/s40747016-0021-9.

[32]. L. Donaldson, The Contingency Theory of Organizations. Sage Publications, 2001.
[33]. N. S. Umanath, "The concept of contingency beyond 'It depends': Illustrations from IS research stream," Inf. Manag., 2003, doi: 10.1016/S03787206(02)00080-0.

[34]. R. E. Freeman, Strategic Management: A Stakeholder Approach, vol. 1. 1984.

[35]. L. G. Tornatzky, M. Fleischer, and A. K. Chakrabarti, The processes of technological innovation. Lexington Books, 1990.

[36]. J. Collis and R. Hussey, Business research: A practical guide for undergraduate and postgraduate students. 2013.

[37]. R. Weber, "The rhetoric of positivism versus interpretivism: A personal view," Mater. Relig., 2004, doi: Editorial.

[38]. Y. Lincoln, S. Lynham, and E. Guba, "Paradigmatic controversies, contradictions, and emerging confluences, revisited," Denzin HK, Lincoln YS. ..., 2003.

[39]. J. W. Creswell, Research design: Qualitative, quantitative, and mixed methods approaches. 4th Edition. 2014.

[40]. A. Bhattacherjee, Social Science Research: Principles, Methods, and Practices - viewcontent.cgi. 2012.

[41]. M. Saunders, P. Lewis, and A. Thornhill, Research Method For Business Students Seventh Edition. 2016.

[42]. A. Bryman and E. Bell, "Business Research Methods," Methods, vol. 3, no. 1, p. 595, 2007, doi: $10.4135 / 9780857028044$.

[43]. R. K. Yin, Qualitative research from start to finish. 2016.

[44]. J. Mouton, "How to succeed in your masters and doctoral studies: SA guide and research book," 2005. Accessed: Jul. 13, 2020. [Online]. Available: https://www.vanschaik.com/book/4e95949a91b0f.

[45]. E. Babbie, The practice of social research. Wadsworth Cengage, 2013.

[46]. B. Fawcett and J. Hearn, Researching others: Epistemology, experience, standpoints and participation, vol. 7, no. 3. 2004.

[47]. D. Black, G. Gates, S. Sanders, and L. Taylor, "Demographics of the gay and lesbian population in The United States: Evidence from available systematic data sources," in Queer Economics: A Reader, 2013.

[48]. C. Kothari, Research methodology: methods and techniques. 2004.

[49]. S. E. Baker and R. Edwards, "How many qualitative interviews is enough?," Natl. Cent. Res. Methods Rev. Pap., 2012, doi: 10.1177/1525822X05279903.

[50]. V. Braun and V. Clarke, "Using thematic analysis in psychology," Qual. Res. Psychol., 2006, doi: 10.1191/1478088706qp063oa.

[51]. S. Tracy, "Data analysis basics: A pragmatic iterative approach," in Qualitative Research Methods: Collecting Evidence, Crafting Analysis, Communicating Impact, 2012.

[52]. M. Armbrust et al., "A view of cloud computing," Commun. ACM, vol. 53, no. 4, p. 50, 2010, doi: $10.1145 / 1721654.1721672$. 
[53]. M. Miller, Cloud Computing: Web-Based Applications That Change the Way You Work and Collaborate Online. Indianapolis: Que Publishing, 2009.

[54]. H. Erdogmus, "Cloud Computing: Does Nirvana Hide behind the Nebula?," IEEE Softw., vol. 26, no. 2, pp. 4-6, Mar. 2009, doi: 10.1109/MS.2009.31.

[55]. A. Mital, J. Pearce, and R. Robinson, Strategic Management: Formulation, Implementation and Control (SIE). Tata McGraw-Hill, 2009.

[56]. H. P. Borgman, B. Bahli, H. Heier, and F. Schewski, "Cloudrise: Exploring cloud computing adoption and governance with the TOE framework," in Proceedings of the Annual Hawaii International Conference on System Sciences, 2013, pp. 4425-4435, doi: 10.1109/HICSS.2013.132.

[57]. D. C. Hambrick and A. A. Cannella, "Strategy Implementation as Substance and Selling," Acad. Manag. Perspect., vol. 3, no. 4, pp. 278-285, Nov. 1989, doi: 10.5465/ame.1989.427740.

[58]. R. DePietro, E. Wiarda, and M. Fleischer, "The context for change: Organization, Technology and Environment," in The process of technology innovation, 1990. 